\title{
Optimasi Jumlah Kedatangan Bus Transjakarta Koridor 1 untuk Melayani Penumpang pada Jam Sibuk Menggunakan Simulasi
}

\section{Optimization the Number of Arrivals Transjakarta Corridor 1 Bus to Serve Passengers at Peak Hours Using Simulation}

\author{
Mirna Lusiani ${ }^{1 *}$ dan William ${ }^{2}$ \\ ${ }^{1}$ Program Studi Teknik Logistik, Universitas Pertamina, Jl. Teuku Nyak Arief, Grogol Selatan, Jakarta Selatan \\ 12220, Indonesia \\ ${ }^{2}$ Program Studi Teknik Industri, Universitas Bunda Mulia, Jl. Lodan Raya No. 2 Ancol, Jakarta Utara 14430, \\ Indonesia
}

Diterima: 8 Mei, 2020 / Disetujui: 20 Juli, 2020

\begin{abstract}
Public transportation plays an important role in meeting people's needs for traveling. In a big city like DKI Jakarta, public transportation plays an important role in supporting the daily activities of its people. Transjakarta is one of the mass public transportation (bus rapid transit) provided by the local government for the community. One of the corridors that have the highest number of passengers is corridor 1 which serves the Blok $M$ - Kota route. The problem that occurs is the irregularity in the scheduling system and the operation of the buses which are considered to be less than optimal, as a result, many buses are idle or buses travel but only carry a few passengers, especially during peak hours on weekdays. To solve this problem, it is necessary to conduct research that regulates the scheduling of bus arrivals at peak hours to serve a large number of passengers. The method used in this research is a simulation by determining the headway timing and determining the number of buses to operate as optimally as possible. The proposed simulation is made of 3 new scenarios and 1 proposed scenario for real-time conditions. Based on the simulation results, the determination of the headway time of 9 minutes between arrivals and 13 buses used during rush hour, from the previous one with a headway time of 4 minutes between arrivals, but the buses used are 30 buses during peak hours. This proposal given is to save bus usage and maximize the utility of the bus.
\end{abstract}

Keywords: Simulation, ProModel, Transjakarta, Bus rapid transit, Headway

\begin{abstract}
ABSTRAK
Transportasi umum berperan penting dalam memenuhi kebutuhan masyarakat untuk berpergian. Di kota besar seperti DKI Jakarta, transportasi umum memiliki peranan yang penting dalam menunjang aktivitas kesehariannya masyarakatnya. Transjakarta merupakan salah satu transportasi umum massal (Bus Rapid Transit) yang disediakan oleh Pemerintah daerah untuk masyarakat. Salah satu koridor yang memiliki jumlah penumpang terbanyak yang dilayani oleh Transjakarta yaitu koridor 1 yang melayani rute Blok $\mathrm{M}$ - Kota. Permasalahan yang terjadi adalah tidak teraturnya sistem penjadwalan dan pengoperasian bus yang dirasa kurang maksimal, akibatnya bus banyak yang menganggur atau bus melakukan perjalanan tetapi hanya mengangkut sedikit penumpang khususnya saat jam sibuk pada hari kerja. Untuk mengatasi permasalahan ini, perlu dilakukan penelitian yang mengatur mengenai penjadwalan kedatangan bus pada waktu sibuk agar dapat melayani penumpang dalam jumlah yang banyak. Metode yang digunakan yang digunakan dalam penelitian ini adalah simulasi menggunakan ProModel dengan penentuan waktu headway dan penentuan jumlah bus agar dapat beroperasi semaksimal mungkin. Simulasi sistem usulan dibuatkan 3 skenario baru dan 1 skenario usulan untuk kondisi real time. Berdasarkan hasil simulasi, didapatkan penentuan waktu headway 9 menit antar kedatangan dan 13 bus yang digunakan di jam sibuk, dari yang sebelumnya dengan waktu headway 4 menit antar kedatangan namun bus yang digunakan adalah 30 bus di jam sibuk. Usulan yang diberikan menghemat penggunaan bus dan memaksimalkan utilitas dari bus tersebut.
\end{abstract}

Kata Kunci: Simulasi, ProModel, Transjakarta, Bus rapid transit, Headway

*email: mirna_lusiani@yahoo.com 


\section{PENDAHULUAN}

Transportasi merupakan salah satu kebutuhan manusia yang dapat membantu setiap orang untuk berpergian dengan jarak yang cukup jauh atau membantu setiap orang untuk sampai ke tempat tujuan dengan waktu tempuh yang cepat. Permasalahan kemacetan lalu lintas merupakan bagian permasalahan transportasi, yaitu terlalu besarnya kebutuhan akan pergerakan dibandingkan dengan prasarana transportasi yang tersedia (Wiyono, 2012). Bertambahnya kendaraan bermotor yang memadati lalu lintas jalan raya dapat menyebabkan terjadinya kemacetan. Kemacetan sendiri dapat menimbulkan kerugian terutama dalam hal efisiensi waktu, karena setiap pengguna jalan raya terpaksa menghabiskan waktunya dalam perjalanan akibat kemacetan yang terjadi dan akhirnya berakhir pada kerugian materi. Hal ini disebabkan dengan terjadinya kemacetan maka tarif angkutan umum tertentu akan naik (seperti taksi, ojek online, dan lain sebagainya), penggunaan bahan bakar kendaraan pribadi semakin tinggi, waktu perjalanan yang semakin lama, kurir pengiriman pada jalur darat menjadi terhambat, dan masih banyak lagi kerugian lainnya yang disebabkan oleh kemacetan yang terjadi, khususnya di daerah perkotaan. Jakarta merupakan kota dengan tingkat kemacetan terparah di Indonesia dengan akumulasi lama waktu yang dihabiskan karena kemacetan adalah sebanyak 63 jam/tahun dan persentase waktu yang dihabiskan adalah $20 \%$ setiap harinya. Persentase ini menjelaskan bahwa rata-rata penduduk di ibukota Jakarta yang menggunakan kendaraan di jalan, menghabiskan $20 \%$ dari waktunya setiap tahun terjebak di dalam kemacetan.

Salah satu upaya pemerintah untuk mengurangi kemacetan adalah dengan membangun sarana transportasi umum massal. Salah satu transportasi umum massal yang pertama kali dibangun oleh pemerintah adalah Transjakarta, yaitu transportasi umum massal Bus Rapid Transit (BRT). BRT telah muncul sebagai sistem transportasi yang lebih ekonomis dan berkontribusi pada peningkatan mobilitas perkotaan (Tomaz de Aquino et al., 2018). Transjakarta dibangun dengan suatu sistem angkutan umum massal yang menggunakan jalur khusus agar perjalanannya tidak terhambat oleh kemacetan kendaraan pribadi. Di sisi lain, Transjakarta merepresentasikan suatu angkutan kota yang dapat mengubah budaya transportrasi yang tidak manusiawi dengan diperkenalkannya nilai-nilai baru bertransportasi, seperti perilaku dan sikap disiplin, dalam menggunakan bis Transjakarta merupakan suatu tatanan baru yang sangat dibutuhkan oleh masyarakat secara menyeluruh. Transportasi umum bus Transjakarta diharapkan dapat memberikan solusi khususnya bagi masyarakat Ibukota karena lokasi dari setiap halte yang ditempatkan jaraknya dekat dengan daerah perkantoran, tempat wisata, dan titik-titik penting lainnya di Ibukota Jakarta. Selain itu, biaya untuk menggunakan jasa transportasi ini juga relatif murah. Namun demikian dengan harga yang relatif murah, angkutan umum massal Transjakarta masih kurang diminati di Jakarta. Hal ini dikarenakan waktu tunggu tiap bus yang cukup lama dan penumpukan penumpang yang terjadi hampir di setiap halte khususnya pada jam-jam sibuk di hari kerja dan overload yang terjadi pada setiap bus di beberapa rute karena kepentingan dan kebutuhan waktu setiap orang yang ingin cepat dan terburu-buru sehingga banyak orang yang kembali memilih untuk menggunakan angkutan pribadi.

Penelitian sebelumnya telah membahas tentang kualitas layanan dari BRT menggunakan analisis faktor (Tomaz de Aquino et al., 2018). Perusahaan diharapkan dapat dengan sigap melayani pelanggan (Sudirga, 2017). Kualitas pelayanan yang diteliti terdiri lima dimensi, antara lain bukti fisik (tangible), kepercayaan (reliability), daya tanggap (responsiveness), jaminan (assurance), dan empati (emphaty) (Wilujeng, Rembulan dan Regina, 2019). Nilai yang baik dari sudut pandang pelanggan dapat dinilai melalui tingkat kepuasan pelanggan (Wilujeng et al., 2019). Penelitian sebelumnya melakukan penilaian pengaruh terhadap kelima dimensi tersebut terhadap kepuasan pelanggan (Rowena, Wilujeng dan Rembulan, 2020). Penelitian sebelumnya menggunakan metode Importance Performance Analysis (IPA) dan Quality Function Deployment (QFD) dalam meningkatkan layanan kualitas (Wilujeng dan Rembulan, 2019).

Pendekatan simulasi dapat diterapkan untuk sistem yang kecil maupun besar (Lusiani dan Chandra, 2018). Pendekatan simulasi telah diaplikasikan baik pada sistem jasa maupun manufaktur untuk melihat perilaku model ketika diterapkan kebijakan tertentu. Simulasi 
digunakan untuk meminimalkan jumlah antrean pada bengkel mobil (Lusiani dan Irawan, 2016) dan Stasiun Pengisian Bahan Bakar Umum (SPBU) (Lusiani dan Belita, 2019). Penelitian sebelumnya menyarankan penambahan operator dalam menanggulangi keterlambatan pekerjaan pada sistem manufaktur (Lusiani dan Filbert, 2019). Isu keterlambatan pekerjaan diselesaikan pada penelitian sebelumnya menggunakan line balancing (Regina, Luin dan Rembulan, 2020). Kebijakan pencampuran biodiesel dan solar disimulasikan menggunakan model matematis pada industri perkebunan (Papilo dan Hartrisari, 2016). Simulasi juga digunakan dalam meningkatkan profit dengan memepertimbangkan kondisi persediaan (Sudirga, 2017).

Isu transportasi telah dibahas dari beberapa sudut pandang yang berbeda. Penelitian sebelumnya membahas tentang jaringan transportasi melalui pipa untuk mengoptimalkan panjang pipa air bersih (Rembulan et al., 2020). Penelitian tentang transportasi diakukan untuk meminimalkan biaya yang didekati dari jarak tempuh (Nurprihatin, Octa, et al., 2019) atau dari waktu tempuh (Nurprihatin, Elnathan, et al., 2019).

Pendekatan simulasi yang digunakan pada sistem transportasi. Skenario kenaikan penumpang digunakan sebagai kondisi yang mungkin terjadi pada commuter line (Lusiani dan Phalen, 2015). Studi sebelumnya menilai faktor-faktor yang memengaruhi waktu tunggu pada masalah kereta api menggunakan Analysis of Variance (ANOVA) dan Tukey's Post Hoc Test (Estember, Pedro dan Tan, 2020). Antrean terjadi karena moda transportasi yang sampai di stasiun pemberhentian sudah penuh dengan penumpang, sehingga penumpang tidak bisa terangkut (Estember, Pedro dan Tan, 2020).

Untuk mengatasi permasalahan yang terjadi saat ini perusahaan harus memecahkan masalah dalam menentukan time headway lewat penjadwalan yang teratur dan menentukan jumlah armada yang dibutuhkan untuk di operasikan pada kurun waktu tertentu. Time headway adalah selisih waktu antar kendaraan yang berada di depan dengan kendaraan yang berada di belakang yang melewati suatu titik tertentu pada satu jalur (Das, Maurya dan Budhkar, 2019). Penentuan time headway melalui penjadwalan dan armada yang di operasikan adalah hal yang penting dalam mengoperasikan dan mengintegrasikan bus Transjakarta. Namun dengan cukup banyaknya pengguna moda transportasi bus Transjakarta, pada kenyataannya seringkali terjadi keterlambatan kedatangan bus Transjakarta sehingga penumpang harus menunggu lama hanya untuk menunggu bus tiba di halte tertentu. Sejak tahun 2004, Transjakarta belum mampu beroperasi pada jadwal yang direncanakan maupun mengejar time headway yang ditargetkan (Nailufar, 2016). Laju aliran dianggap sebagai salah satu faktor utama yang memengaruhi time headway: semakin rendah laju aliran, semakin tinggi time headway (Das, Maurya dan Budhkar, 2019). Oleh karena itu perlu dilakukan penetapan waktu antar kedatangan yang tepat agar penumpang terlayani dengan tepat dan cepat. Dengan demikian utilitas bus akan meningkat dan jumlah bus yang digunakan dapat dioperasikan dengan optimal.

\section{METODOLOGI}

Tahapan dalam penelitian ini digambarkan pada diagram alir pada Gambar 1 .

\subsection{Pengumpulan Data}

Pengumpulan data primer dilakukan pada dua objek yang berbeda. Data primer pertama diperoleh dengan melakukan observasi langsung di tempat observasi yaitu di setiap halte yang berada dalam jalur koridor 1 , dan halte yang diteliti adalah halte dengan pintu bus yang menuju ke arah halte terakhir yaitu Blok M. Data primer kedua diperoleh dengan melakukan observasi langsung di tempat observasi yaitu di setiap lampu lalu lintas yang dilalui oleh bus Transjakarta. Jenis data yang dikumpulkan adalah sebagai berikut.

1. Data jumlah kedatangan penumpang di tiap halte.

2. Jumlah penumpang turun di tiap halte.

3. Lama waktu bus berhenti di tiap halte. 

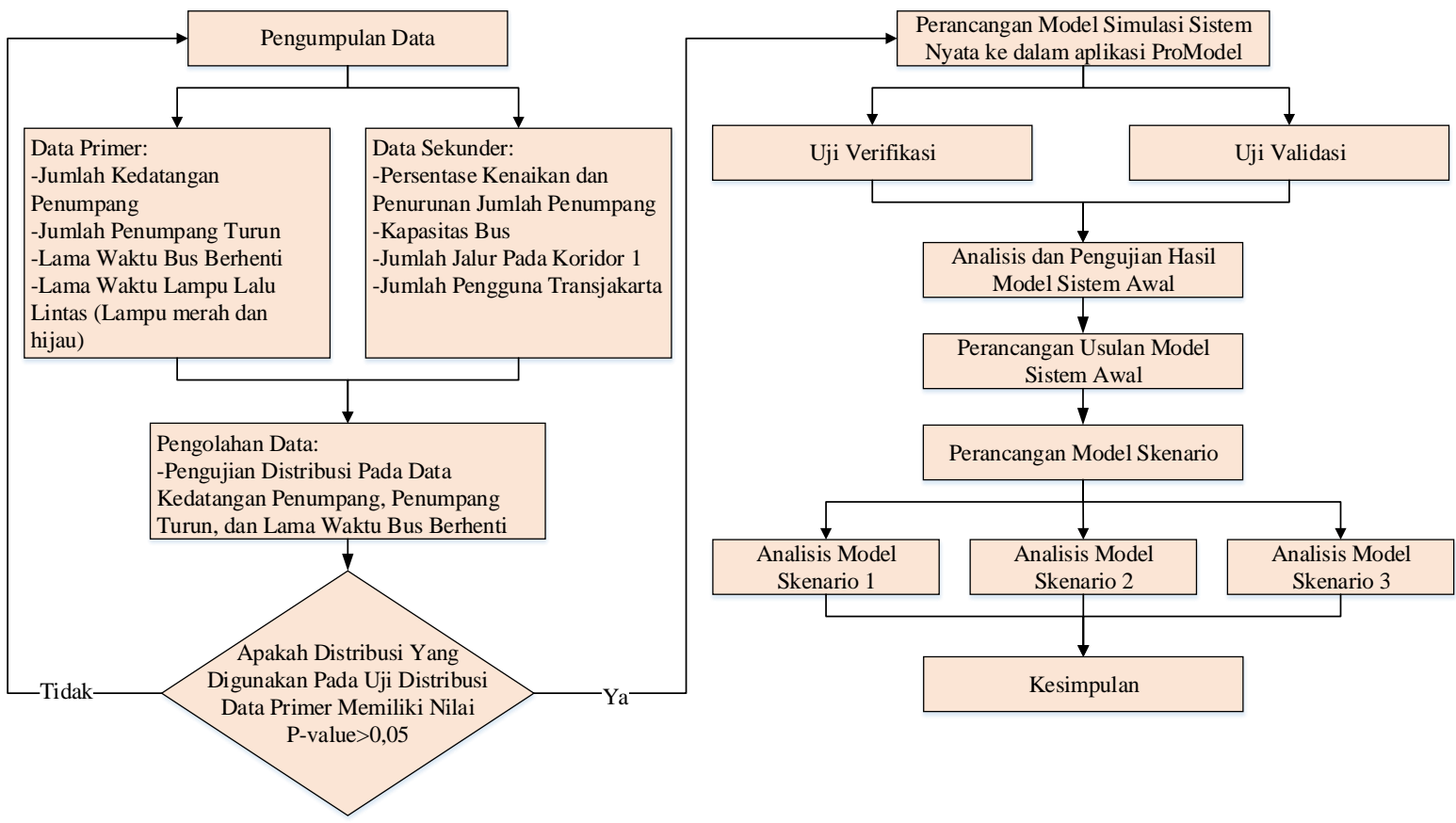

Gambar 1. Diagram Alir Metodologi Penelitian (lanjutan)

\subsection{Pengolahan Data}

Pada tahap ini, data-data yang dikumpulkan akan diolah terlebih dahulu. Pengolahan data dilakukan dengan menggunakan aplikasi Minitab untuk menguji distribusi tiap data. Data yang diolah adalah distribusi jumlah kedatangan penumpang, jumlah penumpang naik, dan lama waktu bus berhenti.

\subsection{Perancangan Model Sistem Awal}

Model simulasi sistem awal dirancang dengan menggunakan perangkat lunak ProModel. Perancangan model simulasi sistem awal disesuaikan dengan kondisi yang terjadi secara aktual di lapangan. Perancangan model sistem awal menggunakan data distribusi jumlah kedatangan di tiap halte, data distribusi jumlah penumpang turun di tiap halte, dan data distribusi lama waktu bus berhenti di tiap halte.

\section{Entities}

Entities berperan sebagai objek yang akan diproses dalam sebuah model simulasi. Terdapat 2 jenis entitas yang digunakan dalam permodelan ini yaitu entitas penumpang dan bus. Penumpang merupakan entitas yang bergerak dan masuk ke dalam bus melalui titik naik dan bergerak bersama dengan bus, kemudian penumpang akan turun pada titik turun di setiap lokasi sesuai dengan distribusi data yang telah ditentukan.
Sedangkan bus merupakan entitas yang bergerak dari satu halte menuju ke halte berikutnya hingga sampai ke titik EXIT.

2. Locations

Locations berperan sebagai tempat dalam sistem yang tidak bergerak. Fungsi dari lokasi adalah sebagai tempat, aktivitas, dan jalur dimana entity diproses. Pada permodelan ini, terdapat 154 lokasi yang digunakan

3. Variables

Variables pada model ini digunakan untuk mengukur jumlah kedatangan penumpang, jumlah penumpang turun, jumlah penumpang naik, total penumpang naik, dan jumlah bus yang digunakan. Variabel dalam perancangan model sistem ini digunakan pada beberapa lokasi tertentu. Pada permodelan ini, terdapat 53 variabel yang digunakan.

4. Arrivals

Arrivals berperan untuk menyatakan kedatangan dari entitas yang akan masuk ke dalam sebuah sistem untuk kedatangan yang pertama kali dari setiap kedatangan.

5. Processing

Processing merupakan segala kegiatan pengolahan input proses yang didefinisikan ke dalam sistem permodelan agar sistem simulasi berjalan (running) sehingga menghasilkan output tertentu. 


\subsection{Verifikasi dan Validasi Model}

Setelah melakukan perancangan model sistem awal, maka selanjutnya akan dilakukan uji verifikasi pada model dengan menggunakan bantuan tombol debug pada saat simulasi sedang di jalankan. Setelah melakukan uji verifikasi perancangan model sistem awal, maka selanjutnya akan dilakukan uji validasi dari hasil output yang direplikasi sebanyak 30 kali. Validasi model dilakukan dengan membandingkan hasil output replikasi simulasi dan data observasi menggunakan uji $\mathrm{T}$ dan uji Chi-square. Model simulasi dinyatakan lolos uji jika nilai dari P-value pada tiap uji tersebut melebihi angka 0,05 sehingga nilai rata-rata dan standar deviasi simulai sistem dinyatakan valid dengan kondisi nyatanya.

\subsection{Perancangan Model Usulan Sistem Awal}

Usulan model sistem awal dirancang dengan tujuan untuk memberikan perbaikan sistem berupa skenario model yang baru. Skenario model yang baru diberikan dengan menentukan waktu antar kedatangan bus yang tepat untuk melayani jumlah penumpang yang harus terlayani dan menentukan jumlah bus yang harus beroperasi.

\subsection{Perancangan Model Skenario}

Model sistem skenario dirancang dengan menggunakan elemen yang sama dengan model sistem awal. Perbedaan model awal dengan model skenario adalah pada model skenario ini menggunakan beberapa kasus seperti terjadi kenaikan dan penurunan persentase jumlah penumpang pengguna layanan bis Transjakarta koridor 1.

\section{HASIL DAN PEMBAHASAN}

\subsection{Simulasi Model Awal}

Dari hasil simulasi model awal, diperoleh hasil dengan waktu antar kedatangan setiap 4 menit, jumlah bus yang digunakan pada permodelan ini adalah sebanyak 30 bus dengan nilai standar deviasi sebesar 0,57 dan dapat melayani sebanyak 7.033 penumpang dengan nilai standar deviasi sebesar 115,75 . Hal ini menunjukkan bahwa simulasi model awal dapat memenuhi kebutuhan penumpang yang harus dilayani, yaitu sebanyak 4.200 penumpang.

Namun dengan waktu antar kedatangan setiap 4 menit, nilai utilisasi dari setiap bus yang digunakan menjadi tidak maksimal. Dapat dilihat bahwa simulasi model awal dapat melayani hingga 7.033 penumpang, dari kebutuhan penumpang yang harus dilayani yaitu hanya 4.200 penumpang. Oleh karena itu, peneliti memberikan usulan dengan melakukan penentuan waktu antar kedatangan yang tepat agar kebutuhan jumlah penumpang yang harus dilayani tercukupi dan jumlah bus yang digunakan dapat dioptimalkan.

Pada penelitian ini diusulkan simulasi dengan menentukan waktu antar kedatangan dari 3 hingga 15 menit. Simulasi dengan waktu antar kedatangan 3 hingga 15 menit bertujuan dalam menentukan waktu antar kedatangan yang tepat untuk melihat jumlah penumpang yang dibutuhkan untuk dilayani dan juga untuk melihat jumlah bus yang digunakan untuk mencukupi kebutuhan jumlah penumpang yang dilayani. Setelah simulasi dijalankan, maka dapat dilihat perbandingan dari setiap time headway yang telah ditentukan, dan kemudian dapat dilakukan penentuan time headway yang terbaik untuk sistem awal dan setiap skenario yang telah dibuat. Berdasarkan simulasi usulan dari model awal, waktu antar kedatangan yang tepat untuk mencukupi jumlah kedatangan penumpang dan mengoptimalkan jumlah kedatangan bus adalah setiap 9 menit dengan jumlah penumpang yang dapat dilayani adalah 4348 penumpang dan jumlah bus yang digunakan adalah sebanyak 13 bus.

\subsection{Simulasi Skenario Kenaikan Persentase Penumpang}

Skenario usulan ini dibuat untuk mencegah terjadinya penumpukan penumpang apabila di masa depan terjadi kenaikan persentase penumpang, dan juga dapat dijadikan sebagai pertimbangan bagi perusahaan untuk menentukan keputusan kedepan bila sewaktuwaktu kenaikan persentase penumpang terjadi.

Dari hasil usulan skenario kenaikan persentase penumpang, terdapat 2 hasil dari 2 skenario. Untuk kenaikan 31\%, jumlah penumpang yang harus terlayani adalah 5.502 penumpang. Dari hasil uji simulasi yang diperlihatkan pada Tabel 1 dengan menentukan waktu antar kedatangan setiap 5 menit, maka jumlah bus yang digunakan adalah sebanyak 24 bus dan jumlah penumpang yang dapat dilayani adalah sebanyak 6.131 penumpang. Untuk kenaikan $50 \%$, jumlah penumpang yang harus terlayani adalah 6.300 penumpang. Dari hasil uji simulasi yang diperlihatkan pada Tabel 2 dengan menentukan waktu antar kedatangan 
setiap 4 menit, maka jumlah bus yang digunakan adalah sebanyak 30 bus dan jumlah penumpang yang dapat dilayani adalah sebanyak 7.033 penumpang.

\subsection{Simulasi Skenario Penurunan Persentase Penumpang}

Skenario selanjutnya adalah skenario usulan yang dibuat apabila terjadi penurunan persentase penumpang. Pengguna angkutan umum mengalami penurunan dari $49 \%$ menjadi
19\% (Faqih, 2019). Hal ini menjadi dasar untuk membuat skenario penurunan penumpang sebesar 30\%. Apabila terjadi penurunan penumpang sebesar 30\%, maka jumlah penumpang yang harus dilayani adalah 2.940 penumpang. Dari hasil simulasi, dengan menentukan waktu antar kedatangan setiap 15 menit, maka jumlah bus yang digunakan adalah sebanyak 8 bus dan jumlah penumpang yang dapat dilayani adalah sebanyak 2.944 penumpang.

Tabel 1. Hasil Simulasi Skenario Kenaikan Penumpang Sebesar 31\%

\begin{tabular}{lccc}
\hline & $\begin{array}{c}\text { Jumlah Bus yang } \\
\text { Digunakan }\end{array}$ & $\begin{array}{c}\text { Waktu antar kedatangan } \\
\text { (Menit) }\end{array}$ & $\begin{array}{c}\text { Total Penumpang Terlayani } \\
\text { (Orang) }\end{array}$ \\
\hline $\begin{array}{l}\text { Hasil } \\
\text { Simulasi }\end{array}$ & 24 & 5 & 6131 \\
$\begin{array}{l}\text { Standar } \\
\text { Deviasi }\end{array}$ & 0,6 & - & 95,88 \\
\hline
\end{tabular}

Tabel 2. Hasil Simulasi Skenario Kenaikan Penumpang Sebesar 50\%

\begin{tabular}{lccc}
\hline & $\begin{array}{c}\text { Jumlah Bus yang } \\
\text { Digunakan }\end{array}$ & $\begin{array}{c}\text { Waktu antar kedatangan } \\
\text { (Menit) }\end{array}$ & $\begin{array}{c}\text { Total Penumpang Terlayani } \\
\text { (Orang) }\end{array}$ \\
\hline $\begin{array}{l}\text { Hasil } \\
\text { Simulasi }\end{array}$ & 30 & 4 & 7033 \\
$\begin{array}{l}\text { Standar } \\
\text { Deviasi }\end{array}$ & 0,57 & - & 115,75 \\
\hline
\end{tabular}

Tabel 3. Hasil Simulasi Skenario Penurunan Jumlah Penumpang Sebesar 30\%

\begin{tabular}{ccc}
$\begin{array}{c}\text { Jumlah Bus yang } \\
\text { Digunakan }\end{array}$ & $\begin{array}{c}\text { Waktu antar kedatangan } \\
\text { (Menit) }\end{array}$ & $\begin{array}{c}\text { Total Penumpang Terlayani } \\
\text { (Orang) }\end{array}$ \\
\hline 8 & 15 & 2944 \\
0,4 & - & 51,48 \\
\hline
\end{tabular}

\section{SIMPULAN}

Model sistem awal atau sebenarnya dari bus Transjakarta koridor 1 rute Kota-Blok M memiliki waktu antar kedatangan bus setiap 4 menit dengan jumlah bus yang digunakan adalah sebanyak 30 bus dan dapat melayani 7.033 penumpang. Usulan terbaik untuk skenario model awal adalah skenario dengan waktu antar kedatangan bus setiap 9 menit dengan jumlah bus yang digunakan sebanyak 13 bus dan dapat melayani 4.348 penumpang dari total kebutuhan jumlah penumpang yang harus dilayani, yaitu sebanyak 4.200 penumpang.

Usulan waktu antar kedatangan dan jumlah bus yang terbaik untuk melayani penumpang apabila terjadi kenaikan penumpang sebesar $31 \%$ adalah waktu antar kedatangan bus setiap 5 menit dengan jumlah bus yang digunakan sebanyak 24 bus dan dapat melayani 6.131 penumpang dari total kebutuhan jumlah penumpang yang harus dilayani, yaitu sebanyak 5.502 penumpang. Usulan waktu antar kedatangan dan jumlah bus yang terbaik untuk melayani penumpang apabila terjadi kenaikan penumpang $50 \%$ adalah waktu antar kedatangan bus setiap 4 menit dengan jumlah bus yang digunakan sebanyak 30 bus dan dapat melayani 7.033 penumpang dari total kebutuhan jumlah penumpang yang harus dilayani, yaitu sebanyak 6.300 penumpang. Usulan waktu antar kedatangan dan jumlah bus yang terbaik apabila terjadi penurunan jumlah penumpang sebesar $30 \%$ adalah waktu antar kedatangan bus setiap 15 menit dengan jumlah bus yang digunakan 
sebanyak 8 bus dan dapat melayani 2.944 penumpang dari total kebutuhan jumlah penumpang yang harus dilayani, yaitu sebanyak 2.940 penumpang.

Karena desain stasiun pemberhentian tergantung pada lokasinya (Estember, Pedro dan Tan, 2020), maka penelitian selanjutnya dapat mempertimbangkan kedatangan bus koridor lain yang melewati koridor 1 dan penelitian dilakukan unuk rute dua arah yaitu Blok M Kota - Blok M. Beberapa lokasi yang dilewati akan memiliki kapasitas penumpang yang berbeda-beda.

\section{DAFTAR PUSTAKA}

Das, S., Maurya, A. K. dan Budhkar, A. K. (2019) "Determinants of Time Headway in Staggered Car-following Conditions," Transportation Letters. Taylor \& Francis, 11(8), hal. 447-457. doi: 10.1080/19427867.2017.1386872.

Estember, R. D., Pedro, H. B. S. S. dan Tan, J. C. L. (2020) "Operational Efficiency Model for a Railway Transit in the Philippines," in Proceedings of the 2020 2nd International Conference on Management Science and Industrial Engineering. Osaka: ACM International Conference Proceeding Series, hal. 319325. doi: 10.1145/3396743.3396798.

Faqih, F. (2019) Anies Sebut Pengguna Transportasi Umum di Jakarta Turun 30 Persen, merdeka.com. Tersedia pada: https://www.merdeka.com/jakarta/aniessebut-pengguna-transportasi-umum-dijakarta-turun-30-persen.html (Diakses: 4 Mei 2020).

Lusiani, M. dan Belita, A. (2019) "Mengurangi Antrean pada Stasiun Pengisian Bahan Bakar Umum dengan Pendekatan Simulasi Menggunakan ProModel," Journal of Industrial Engineering and Management Systems, 12(1), hal. 32-41. doi: 10.30813/jiems.v12i1.1534.

Lusiani, M. dan Chandra, S. (2018) "Optimasi Jumlah Kedatangan KRL Commuter Line untuk Mengatasi Penumpukan Penumpang Jalur Bekasi - Jakarta Kota Menggunakan Simulasi Promodel," Journal of Industrial Engineering and Management Systems, 11(1), hal. 32-38. doi: 10.30813/jiems.v11i1.1014.

Lusiani, M. dan Filbert, K. (2019) "Penentuan Jumlah Operator Untuk Mengurangi
Keterlambatan pada Proses Pengemasan Menggunakan Simulasi ProModel," Journal of Industrial Engineering and Management Systems, 12(2), hal. 109114. doi: 10.30813/jiems.v12i2.1669.

Lusiani, M. dan Irawan, R. A. (2016) “Analisis Sistem Antrian pada Bengkel Mobil Menggunakan Simulasi," Journal of Industrial Engineering and Management Systems, 9(2), hal. 96-108.

Lusiani, M. dan Phalen, E. (2015) "Penentuan Jumlah Kedatangan Armada Optimal KRL Commuter Line Jalur BekasiManggarai untuk Skenario Kenaikan Jumlah Penumpang Menggunakan Simulasi ProModel," Journal of Industrial ENgineering and Management Systems, 8(2), hal. 32-39.

Nailufar, N. N. (2016) Mengapa Transjakarta Sulit Tepat Waktu?, Kompas.com. Tersedia pada: https://megapolitan.kompas.com/read/20 16/08/29/08484881/mengapa.transjakarta .sulit.tepat.waktu.?page=all (Diakses: 4 Mei 2020).

Nurprihatin, F., Elnathan, R., et al. (2019) "A Distribution Strategy Using A Two-step Optimization to Maximize Blood Services Considering Stochastic Travel Times," in IOP Conference Series: Materials Science and Engineering. IOP Publishing Ltd. doi: 10.1088/1757899X/650/1/012043.

Nurprihatin, F., Octa, A., et al. (2019) "The Extension Analysis of Natural Gas Network Location-routing Design Through the Feasibility Study," Journal of Applied Research on Industrial Engineering, 6(2), hal. 108-124. doi: 10.22105/jarie.2019.174164.1082.

Papilo, P. dan Hartrisari, H. (2016) "Simulasi Model Matematik Dampak Penerapan Kebijakan Mandatori Blending BiodieselSolar terhadap Kebutuhan Lahan Perkebunan Kelapa Sawit dan Tingkat Emisi CO2," Journal of Industrial Engineering and Management Systems, 9(2), hal. 140-154. doi: 10.30813/jiems.v9i2.44.

Regina, T., Luin, J. A. dan Rembulan, G. D. (2020) "Mengurangi Keterlambatan Waktu Produksi Menggunakan Line Balancing pada Sektor Konstruksi Jalan Tol," in Prosiding Seminar Nasional 
Riset dan Teknologi. Jakarta: Universitas Indraprasta PGRI, hal. 258-263.

Rembulan, G. D. et al. (2020) "Optimalisasi Panjang Jaringan Pipa Air Bersih di DKI Jakarta Menggunakan Minimum Spanning Tree," Jurnal Intech, 6(1), hal. 75-87. doi: 10.30656/intech.v6i1.2164.

Rowena, J., Wilujeng, F. R. dan Rembulan, G. D. (2020) "Pengaruh Kualitas Layanan dalam Menciptakan Kepuasan Publik di Kantor Pelayanan Publik, Jakarta Utara," Journal of Industrial Engineering and Management Systems, 13(1), hal. 27-34. doi: 10.30813/jiems.v13i1.2083.

Sudirga, R. S. (2017) “Analisis Persediaan untuk Menentukan Profit dan Tingkat Pelayanan dengan Metode Simulasi," Journal of Industrial Engineering and Management Systems, 10(2), hal. 103110. doi: 10.30813/jiems.v10i2.764.

Tomaz de Aquino, J. et al. (2018) "Factors that Influence the Quality of Services Provided by the Bus Rapid Transit System: A Look for User's Perception," Benchmarking, 25(9), hal. 4035-4057. doi: 10.1108/BIJ-12-2017-0344.

Wilujeng, F. R. et al. (2019) "Meningkatkan
Kepuasan Pelanggan pada Dua Bisnis ECommerce Terbesar di Indonesia dengan Menggunakan Analisis Servqual dan IPA," in Prosiding Seminar Nasional Sains dan Teknologi. Jakarta: Fakultas Teknik Universitas Muhammadiyah Jakarta, hal. 1-9.

Wilujeng, F. R. dan Rembulan, G. D. (2019) "Perancangan Model Kualitas Pelayanan Puskesmas dengan Metode Importance Performance Analysis (IPA) dan Quality Function Deployment (QFD)," Jurnal Intech, 5(2), hal. 43-50. doi: 10.30656/intech.v5i2.1675.

Wilujeng, F. R., Rembulan, G. D. dan Regina, T. (2019) "Pengukuran Kualitas Layanan dengan Metode Service Quality pada Puskesmas Jakarta Utara," in Prosiding Seminar Nasional Teknik Industri. Lhokseumawe: Universitas Malikussaleh.

Wiyono, S. (2012) "Penggunaan Sistem Dinamik dalam Manajemen Transportasi untuk Mengatasi Kemacetan di Daerah Perkotaan," Jurnal Transportasi, 12(1), hal. 1-10. 